Board. Replies have now been received, and the Council is asking the Ministry of Health to receive a deputation.

A further interim report on Industrial Eye Diseases and Injuries has been prepared and presented to the Council by the Committee appointed to investigate this subject. The Council hopes that further useful information will be available in a year's time; in the meantime permission has been given for some of the work done to be published, and this has been incorporated in a paper read at the Annual Congress of the Ophthalmological Society of the United Kingdom.

A Committee has been appointed to enquire into the constitution and working of the so-called Refraction Hospitals.

Certain questions of ophthalmic interest have been referred to the Council and have received due consideration.

With a view to enlarging its membership, the Council recommends that there be an increase in the number of members elected annually, and that the rules drawn up for the work of the Council be altered so that there shall be twelve members elected annually, five by the Council of the Ophthalmological Society of the United Kingdom, five by the Council of the Section of Ophthalmology. Royal Society of Medicine, and two by the Oxford Ophthalmological Congress. The Council also recommends an alteration of the rules so that the Executive Committee shall consist of eight members, instead of six, as heretofore.

The Council desires to thank the Council of the Royal Society of Medicine for the use of rooms for meetings, and the National Committee for the Prevention of Blindness (U.S.A.) for continuing to send copies of its publications.

As in former years, the expenses of the Council have been defrayed by contributions from its members.

\title{
REPORT OF THE ANNUAL CONGRESS OF THE OPHTHALMOLOGICAL SOCIETY OF THE UNITED KINGDOM, I929
}

THE Ophthalmological Society of the United Kingdom held its Annual Congress in London at the House of the Royal Society of Medicine, from April 11-13, under the presidency of MR. Charles Howard Usher.

The Transactions of the Society publish a full account of the papers and discussions : merely an indication of these is given here.

The first paper was read by Mr. Treacher Collins on "Formative fibrous tissue reaction in the eye." $\mathrm{Mr}$. Treacher Collins classified the conditions giving rise to this reaction as follows : 
(1) Encapsulating fibrosis : found in connection with foreign bodies, neoplasms, and parasitic cysts.

(2) Post-fibrinous fibrosis in connection with blood clots.

(3) Reparative fibrosis found in connection with developmental defects, the healing of wounds, and as a sequel to granulomatous inflammation.

Mr. F. A. Willinison-Noble read a paper on "Graded Squint Operations," in which he described his procedures for muscle advancement according to the results of measurement. To measure the angle of deviation he uses the Maddox tangent scale, and also works with the Maddox rod and prisms. He advocates operation under general anaesthesia and approves of the results of recessions.

Mr. M. Hepburn read a paper on " Some unsolved problems in connection with diseases of the choroid." He maintains that primary pigmentary degeneration of the retina is not due to nerve degeneration (the abiotrophic theory of 'Treacher Collins and others) but to defects in the choroidal circulation. Mr. Hepburn explained how the variations and the sector-shaped defect in the visual fields were brought about in cases where there existed inflammatory deposits and scars in the choroid. He believes that vascular diseases of the choroid are more likely to end in optic atrophy than the inflammatory forms. Mr. Treacher Collins discussed the paper at length.

Mr. Clark Souter reported a case of uveo-parotid fever, and gave an account of the autopsy findings.

Thursday Afternoon was devoted to a discussion on " Heterophoria."

Dr. E. E. MADDox (Bournemouth) defined orthophoria as " a tendency of the eyes to set themselves truly at the object of fixation," and heterophoria as a departure from this. He stated that there are 12 species of paretic heterophoria, and twelve of concomitant. When testing for heterophoria Dr. Maddox emphasised the importance of keeping the disc of rods perpendicular to the line between the eye and the light. He has found it convenient to use a hand trial frame, which could be held in front of the ordinary trial frame, the former having rods on one side and a rotating prism or pair of prisms on the other. He maintains that it is impossible to make rigid rules for the treatment of this condition. Most minor degrees of heterophoria do not need treatment. Attention to the general health, foci of infection, and the correction of refractive errors is advocated. If refractive treatment fails, the choice lies between exercises or prisms; the former are more suitable for the young, and the latter for the old. A weak prism for a high degree of exophoria is often 
of great value as it is the last degree of stretch on the fusion reflex that is the most fatiguing. Operation is suitable in selected cases.

Mr. Charles Goulden followed and said that it was important to be certain of the type of deviation, i.e., concomitant or paralytic. He stated that hyperphoria causes the most inconvenience of all the heterophorias, but that only when the vertical deviation produces symptoms should it be treated, and then by prisms. If the prism needed for correction was $2^{\circ}$ or more it should be equally divided between the two eyes, the base being downwards before the affected eye and upwards for the other. The high degrees of hyperphoria might need operation. Mr. Goulden described four patients suffering from torticollis due to hyperphoria, and a patient suffering from spasm of convergence due to hysteria.

Group-Captain E. C. Clements (R.A.F.) spoke of his experiences in the Air Force, where pilots in spite of having good vision make faulty landings. He believes that this is due to defective muscle balance, and that heterophoria is influenced by malaria, sand-fly fever, and other conditions in tropical countries. The men are treated by exercises.

Mr: ERnest Clarke said that in the civil population heterophoria was very common, but, as it was usually of a minute degree, it was unimportant. When minus glasses were necessary there might be a slight degree of exophoria, for these glasses always lowered the amplitude of convergence.

MR. H. B. GRIMSDale said that patients suffering from heterophoria were sometimes greatly helped by $0.25 \mathrm{cyl}$. and by a $1^{\circ}$ prism.

Mr. Humphrey Neame agreed that in hyperphoria a prism of the lowest degree possible should be used in order to relieve discomfort.

Mr. HARRISON BUTLER said that for elderly patients with convergence insufficiency the relief afforded by the prisms allowed the muscles to repair, and that later the prism could be discarded.

Mr. Williamson-Noble described his method of testing for cyclophoria by means of tilted mirrors.

ON Friday, April 12, Mr. W. S. Duke-Elder read a paper on " The Nature of the Vitreous," illustrated by the epidiascope.

He described the structure of the vitreous as seen by the slit-lamp and the ultra-microscope, an instrument first utilised in this study in 1923. The vitreous is a pure homogeneous gel, i.e., of the consistency of gelatin, and it is derived chiefly from the ectoderm in the vitreous cavity. On the surface of the vitreous are forces which aggregate together the micelle in close formation. In most cases the chemical composition of the vitreous is the same as that of the aqueous in regard to the nitrogen and salt content, but in addition 
there is present a muco-protein to keep it transparent, and a keratoprotein to preserve it in the state of a gel.

Mr. MAURICE Whiting read a paper on " Optic atrophy following haemorrhage from the alimentary tract." He said that the condition might follow haemorrhage from any source, but that it was more commonly a sequel to bleeding in the alimentary tract or from the uterus. In his opinion the atrophy was due to the sudden death of the nerve fibres.

Miss MANN gave an interesting demonstration of the phylogenetic value of the lower visual field.

Mr. EUGENE WOLFF contributed a paper on " The pathology of orbital haemorrhage and inflammation." He believes that the delayed absorption is due to the fact that the orbital fat is poorly supplied by blood vessels, and that when the muscles of the eye have yielded to the full extent of their elasticity the orbit becomes a closed space and that the increased intra-orbital pressure brings about compression of the veins, giving rise to venous stasis, transudation, and delayed absorption.

Mr. G. F. AleXANDER gave a lecture on the great antiquity of removal of cataract, and offered suggestions on the instrumentation of cataract operations.

Friday Evening was devoted to a discussion on the diagnosis and treatment of ocular tuberculosis.

Sir ARNold Lawson opened the discussion. He pointed out that ocular tuberculosis as an accompaniment of phthisis was very uncommon, and that the most common tuberculous lesion of the eye is iridocyclitis. He opposed the use of Calmette's local conjunctival test as being too dangerous. He dealt with the treatment from the general and local points of view. Sir Arnold gave statistics of 42 cases treated with tuberculin, 10 per cent. of whom showed no improvement, and in 45 per cent. healing followed its use. He spoke of the good that followed photo-therapy and mentioned that the value of local ultra-violet rays was still sub judice.

DR. R. A. Young dealt with the systemic aspect of the disease. He advised caution in tuberculin treatment, and said that in the active stages both tuberculin and artificial sunlight could do harm.

Mr. S. H. BrownING dealt with the subject from the bacteriological point of view. He spoke of the difficulty in diagnosis. He had used bovine and human tuberculin in the treatment of ocular tuberculosis for 15 years and had little doubt as to its value.

Mr. A. L. WhITEHEAD emphasised the importance of a thorough search for a tuberculous lesion elsewhere in the body when ocular tuberculosis was suspected. He believed in the value of tuberculin treatment when begun very gradually.

Mr. W. S. DUKE-EldER said that he regarded phototherapy as an adjunct to ordinary treatment. He gave statistics of 33 cases treated at Moorfields. 
Dr. G. Mackay and Mr. M. S. Mayou also took part in the discussion.

On Saturday, April 13, Mr. Bernard Cridland opened a discussion on "Minor eye injuries in industry." He divided the cases into three main groups :-

(1) Small flying particles. Grindstones, emery wheels, etc.: 51 per cent.

(2) Flying chips of metal. 26 per cent.

(3) Miscellaneous. Mining, road making, general labour, etc. : 23 per cent.

In 70 per cent. of the cases there was no protection used; in 19 per cent. protection was supplied but not used; and in 11 per cent. protection was used but was ineffective.

$\mathrm{Mr}$. Cridland suggested three main lines of prevention :

(1) Mechanical guarding.

(2) Education of workmen and foremen in this subject.

(3) Engineering revision.

He said that good goggles afforded 100 per cent. protection and mechanical shields 90 per cent.

Mr. J. H. Fisher, Mr. Treacher Collins, Mr. John Rowan, Mr. Cyril Walker, Mr. J. F. Cunningham, Mr. M. Hine, Dr. G. Mackay, and Mr. A. L. Whitehead discussed this subject, and Sir John Parsons pointed out that American employers in engineering shops took a stronger line than British employers in insisting on workmen using adequate protection.

A clinical meeting was held at the Royal Westminster Ophthalmic Hospital and many interesting cases discussed.

A visit was made to the National Physics Laboratory at Teddington.

During the Congress two rooms were set apart as a museum for ophthalmic appliances, pathological specimens, drawings, and literature. The exhibits included goggles damaged during use at various trades.

The Annual Dinner was held at the Langham Hotel on Thursday, April 11. The President, Mr. Charles Howard Usher, took the chair and proposed the health of the Society. He gave a most interesting survey of the history of the Society and its distinguished members in the past. He presented to us a forecast of a future Congress, which might avail itself of the advantages afforded by travelling at record speed in the air or on land, and obtain the presence of eminent foreign ophthalmologists at a few hours notice. This toast was responded to by $\mathrm{Mr}$. Treacher Collins who touched humorously on the foresight shown by those " original members " who many years ago compounded for their life membership in the place of an annual subscription and thereby had scored financially. He also related how the fund for the Tran- 
sactions came to benefit as a result of the bomb outrage in Bartholomew Close during one of the German air raids, when certain copies of the Transactions, destined for the libraries of ophthalmologists in enemy countries were destroyed, but fortunately were covered by insurance.

Mr. J. B. Lawford proposed the health of the President and Chairman.

At the Annual General Meeting the following officers were elected for 1929-1930 :

President : Leslie Paton; Vice-Presidents : A. L. Whitehead, Rayner D. Batten, W. H. McMullen, O.B.E., C. H. Usher; Treasurer : Sir Arnold Lawson, K.B.E.; Council : C. Goulden, O.B.E., A. F. MacCallan, C.B.E., J. Jameson Evans, Lt.-Col. A. E. J. Lister, H. P. Gibb, P. G. Doyne, and Presidents of Affiliated Societies; Secretaries : M. L. Hine, M. H. Whiting, O.B.E.

Professor Elliot Smith was elected an honorary member of the Society.

A resolution was passed to the effect that all past presidents of the Society should be members of the Council (ex-officiis).

\section{ABSTRACTS}

\section{I. -UVEA}

(1) Bistis, J. (Athens).-A clinical and experimental study concerning the role of the sympathetic in the aetiology of heterochromia. (Etude clinique et experimentale sur le role du sympathique dans l'étiologie de l'hétérochromie.) Arch. d'Ophtal., September, 1928.

(1) An abstract of the usual length would give a wholly inadequate interpretation of this long and interesting communication. It is in two parts : (1) Clinical-in which Bistis deals in detail with cases recorded by himself and many other writers and their bearing on the question under discussion: (2) Experimental-in which the results of experiments and observations on animals, carried out by Bistis and others are recorded and discussed. This latter part is illustrated by photographs of the eyes and irides of rabbits.

The author's "conclusions" are :-

(1) Congenital or acquired heterochromia, when not preceded by intra-ocular inflammation, should be regarded as the sequel of paralysis of the cervical sympathetic; this is demonstrated by clinical evidence and corroborated by experiments on rabbits by removal of the superior cervical ganglion. 